(C) The Author 2013. The online version of this article is published within an Open Access environment subject to the conditions of the Creative Commons Attribution-NonCommercial-ShareAlike licence $<$ http://creativecommons.org/licenses/by-nc-sa/3.0/>. The written permission of Cambridge University Press must be obtained for commercial re-use.

\title{
State of play in direct-to-consumer genetic testing for lifestyle-related diseases: market, marketing content, user experiences and regulation
}

\author{
Paula Saukko \\ Department of Social Sciences, Loughborough University, Brockington Building, Loughborough LE11 3TU, UK
}

\begin{abstract}
Direct-to-consumer (DTC) genetic tests have aroused controversy. Critics have argued many of the tests are not backed by scientific evidence, misguide their customers and should be regulated more stringently. Proponents suggest that finding out genetic susceptibilities for diseases could encourage healthier behaviours and makes the results of genetics research available to the public. This paper reviews the state of play in DTC genetic testing, focusing on tests identifying susceptibilities for lifestyle-related diseases. It will start with mapping the market for the tests. The paper will review (1) research on the content of the online marketing of DTC tests, (2) studies on the effects of DTC genetic tests on customers and (3) academic and policy proposals on how to regulate the tests. Current studies suggest that the marketing of DTC genetic tests often exaggerates their predictive powers, which could misguide consumers. However, research indicates that the tests do not seem to have major negative effects (worry and confusion) but neither do they engender positive effects (lifestyle change) on current users. Research on regulation of the tests has most commonly suggested regulating the marketing claims of the companies. In conclusion, the risks and benefits of DTC genetic tests are less significant than what has been predicted by critics and proponents, which will be argued reflects broader historical trends transforming health and medicine.
\end{abstract}

Direct-to-consumer genetic testing: Nutrigenetics

Direct-to-consumer (DTC) genetic tests are sold directly to the consumer, without the mediation of a healthcare professional, typically via the Internet. The tests have attracted both positive and negative publicity. In 2008, the Time Magazine named the DTC whole genome scan sold by the company 23andMe the 'Innovation of the Year.' However, it has been noted that the scientific evidence supporting the association between a gene variant and a disease or preventive advice for many of the DTC genetic tests is limited $^{(1)}$. For this reason, the tests have been criticised for misleading the public and for potentially making individuals unduly anxious about their future health ${ }^{(2,3)}$. The companies have argued that they may encourage healthy lifestyle and are making the results of investments in genomic research available to ordinary individuals.

Customers purchasing DTC genetic tests usually send a saliva sample to a company and receive their results via mail or uploaded onto an online account. Some DTC genetic testing companies may identify just one gene variant, whereas so-called 'whole genome scans' frequently cover several hundred gene variants. Companies test for a variety of genes associated with susceptibility for diseases, 
Table 1. (a) Companies which offered health or lifestyle related direct-to-consumer (DTC) genetic tests in $2008^{(5)}$ and continued to do so (as of 2012). (b) Companies which were offering health or lifestyle related DTC genetic tests in 2008 but no longer offered health-related DTC genetic tests (as of 2012)

Name of the company

Types of health or lifestyle related DTC genetic tests offered

(a)

23andMe

Genetic Health

Geneticom

Genosense (Christos Pampakerides)

Graceful Earth

Health Tests Direct

Health Check USA

Holistic Health

Kimball Genetics

Medichecks

Quixtar/Interleukin

Suracell

(b)

Acu-Gen Biolab

Consumer Genetics

Cygene Direct

DeCODE

Dermagenetics

DNA Direct

G-Nostics

Genelex

Medigenomics

Mygenome

Navigenics

Salugen

Sciona

Smart Genetics
Whole genome test

Variety of tests, including a nutrigenetic test, UK

Several genetic tests, including tests for haemochromatosis and thrombophilia, unclear delivery, German

Several genetic screens, including a nutrigenetic screen, Cypriot

Genetic test for Alzheimer's disease

Variety of tests, including ApoA1, unclear if DNA or protein tests offered

Variety of tests, including a genetic test for haemochromatosis,

free genetic counselling offered through Kimball Genetics

Variety of tests, including a nutrigenetic test, unclear delivery

Variety of tests, including thrombophilia and ApoE testing, order

through telephone after a discussion with a genetic counsellor

Variety of tests, including genetic tests for thrombophilia and

breast cancer, breast cancer test via physician only, UK

Variety of tests, including a nutrigenetic test

Anti-ageing genetic tests, Italian

Defunct, used to only offer a fetal gender test

Only offers a fetal gender test currently

Defunct

Offers whole genome test via physician only

Offers anti-ageing DNA tests via 'aesthetic physicians' only

Offers genetic tests via physician only

Defunct, offered a genetic test for nicotine addiction

Only offers paternity tests currently

Only offers paternity tests currently, other genetic

tests for industry, German

Defunct (website still exists but not operational)

Whole genome test via physician only

Defunct, offered nutrigenetic tests

Defunct, offered nutrigenetic tests

Defunct traits, ancestry and paternity. Some companies sell 'nutrigenetic' tests, which identify individuals' susceptibilities for lifestyle-related diseases, such as CVD and various cancers, and provide advice on nutrition and supplements. Nevertheless, companies, which do not market their tests as nutrigenetic, also offer dietary advice in conjunction with tests that identify susceptibilities for lifestyle-related diseases. DTC genetic testing websites often link to scientific articles and may contain interactive features, such as user forums. In 2012, the typical price for the tests was several hundred US dollars. In 2011, 23 andMe stated that it had sold 100000 whole genome scans ${ }^{(4)}$.

A 2008 review identified twenty-six 'recent' companies marketing DTC genetic tests, of which all but one (Acu Gen, offering a fetal gender test) offered health or lifestyle related tests (e.g. nutrigenetic tests or tests for disease susceptibility or anti-ageing) ${ }^{(5)}$. To get a sense of the stability of the market, I reviewed the websites in 2012 to see how many were still in operation. Twelve or nearly half of the companies continued to offer DTC genetic tests. Of the remaining fourteen companies, seven had ceased functioning, four offered genetic tests only via a physician and three sold genetic tests not related to health, i.e. paternity and fetal gender tests (see Table 1). These figures indicate not only a fair amount of fluctuation in the market but also the emergence of several companies that have operated for some time (there are also new companies on the market that did not operate in 2008). Nevertheless, the long-term future and shape of the market is less clear, as most of the companies are small and change frequently.

This paper will review the state of play in the marketing of DTC genetic tests, focusing on tests identifying susceptibilities for lifestyle-related diseases. First, the article will review research on the content of the online marketing and sales portals for the tests. Second, I will discuss research on the experiences of customers of DTC genetic testing companies as well as experiences of genetic susceptibility testing more generally. Third, I will review policy and academic proposals on how to regulate DTC genetic tests.

In conclusion, the paper argues that DTC genetic tests embody several historical trends, which are transforming health and medicine. As such, their risks and benefits are less significant than what has been predicted by critics and proponents. 


\section{Content of marketing websites}

One of the main concerns about DTC genetic tests is that they may 'misguide' the public by making overstated claims ${ }^{(2,3)}$. There are several studies that have investigated the content of DTC genetic testing companies, marketing websites and their test results. In 2006, the US Government Accountability Office published a report based on examining the results its investigators received from four nutrigenetic testing companies. The investigators concluded that even if the tests contained disclaimers that they were not intended to diagnose disease, the test results predicted the consumers were at risk of various diseases. To hedge their claims the companies stated the consumers 'may be' at risk. The investigators also criticised the companies for selling overpriced supplements in conjunction with the tests and for making scientifically unsound promises that the supplements could 'repair DNA damage,"3).

In 2010, the Government Accountability Office investigated further four DTC genetic testing companies, including those offering whole genome scans. Its investigators noted that the different companies provided the same consumers (i.e. the same DNA sample was sent to several companies) very different risk profiles for the conditions they claimed to test, such as prostate cancer and hypertension. The Government Accountability Office report also expressed concern about statements in the companies' results that indicated that a consumer had a high risk of cancer. The investigators pointed out that while the companies advertised they would offer further expert advice they often could not offer such advice ${ }^{(2)}$.

Several academic studies have examined the content of DTC genetic testing websites. Lachance et al. ${ }^{(6)}$ analysed twenty-nine such websites and observed that while nearly all $(90 \%)$ stated the benefits of the tests only half $(55 \%)$ presented limitations of the tests. Further, the authors noted that only slightly over a third (38\%) of the sites supported their claims with scientific evidence and, as a consequence, did not often distinguish between tests in a situation, where the clinical validity of the tests varies significantly, i.e. the strength of the association between a gene variant and a disease may be more strongly or weakly supported by evidence. Other studies have presented similar findings. Lewis et $a l{ }^{(7)}$ found that only seven out of the twenty-five DTC genetic testing websites analysed complied with most of the transparency requirements outlined by the American Society for Human Genetics, and less than half (ten out of twenty-five) offered information on the predictive value of the genetic markers being tested. Similarly, Singleton et $a l .{ }^{(8)}$ observed that while many $(74 \%)$ of the twentythree DTC genetic testing websites analysed contained disclaimers about the clinical usage of the tests (i.e. that they are not intended to diagnose disease), only a third $(30 \%)$ discussed current limitations of the predictive ability of the genetic tests. An analysis of sixty-four organisations promoting (even if not always selling) nutrigenomic tests noted that only $13 \%$ presented information on the limitations of the tests and current science behind them ${ }^{(9)}$.

Different companies fared differently in terms of informative content. Both Lachance et al. ${ }^{(6)}$ and Lewis et al. ${ }^{(7)}$ found that whole genome testing companies were more likely to discuss the limitations of the tests ${ }^{(6,7)}$. Whole genome test sites, often containing illustrative graphs, also fared better in terms of readability of the sites, in a situation where most sites were difficult to navigate and understand, with only $7 \%$ using mostly common language ${ }^{(6)}$. However, even the companies, which provided evidence of the predictive value of the test, did not often discuss how little such predictions mattered in the overall puzzle where multiple genetic factors (most of which are yet unknown) and environmental factors interact to produce lifestyle-related diseases ${ }^{(7)}$.

Research has also identified a few common ways in which DTC genetic testing companies frame their services. Liu and Pearson observed that $90 \%$ of the forty-six companies marketing health-related genetic tests online used the emotional appeal of 'empowerment' and being in control $^{(10)}$; other studies have made similar observations ${ }^{(11,12)}$. Based on a qualitative analysis of DTC genetic testing websites, Harvey noted that the discourse on empowerment resonates with the current public health ethos, which emphasises patient's personal responsibility to enhance their health and their ability and entitlement to make choices about their healthcare ${ }^{(11)}$. In another qualitative study of DTC genetic testing websites, Nordgren and Juengst noted that the companies framed their customers as having the 'right to know' their genome, drawing on the 'open source' discourse, which emphasises individuals' right to openly access and share information ${ }^{(13)}$. These results indicate that the companies mobilise the current anti-paternalistic sentiment, according to which individuals should have both the privilege and duty to take care of their own health.

The second most common emotional appeal, after empowerment, on DTC genetic testing websites identified by Liu and Pearson was 'warmth,' used in $60 \%$ of the sites $^{(10)}$. Einsiedel and Geransar observed that the twentytwo DTC genetic testing websites analysed also frequently employed 'credibility markers' to engender trust in the service, such as emphasising the professional credentials of the management team or laboratory accreditation. They also found that nineteen out of twenty-two company websites engendered credibility by making the site easy to navigate ${ }^{(14)}$. Lachance, however, found the websites hard to navigate; only ten out of thirty-four companies providing a search-engine for the site ${ }^{(6)}$.

Several studies have examined whether DTC genetic testing companies offer advice by a physician or genetic counsellor. This is somewhat complicated, as the companies frequently change between offering their services direct or via a physician or other professional, such as a nutritionist. In 2003, Gollust et al. observed that of the fourteen companies marketing health-related genetic testing on the Internet seven offered them direct, and out of those seven, three indicated that they could provide their customers access to a physician's advice if requested. Companies that provided the tests results via a physician tended to offer more tests with significant implications, such as supplementary newborn screening ${ }^{(15)}$. Similarly, Geransar and Einsiedel noted that of the twenty-four companies advertising genetic tests directly to consumers 
those that required physician mediation typically offered risk assessment and diagnostic tests, whereas companies selling the tests direct over the Internet offered 'enhancement' test, such as nutrigenetic tests ${ }^{(16)}$. A recent analysis of the content of twenty-nine DTC genetic testing websites found that four (14\%) provided an opportunity to talk to a healthcare professional before the test and eight $(28 \%)$ offered such an opportunity afterwards ${ }^{(6)}$.

Studies indicate that genetic tests with potentially significant implications, such as newborn screening tests or tests for predisposition to breast cancer, are typically offered via physician, whereas tests with less significant impact, such as nutrigenetic tests, are offered direct. However, similar tests, such as whole genome scans, can be offered both direct (23andMe) or via a physician (Navigenics). Further, when we analysed the websites of nine nutrigenetic testing companies we noted that some of them framed their services as medical (using clinical language and images, such as stethoscopes) and others as lifestyle products (presenting images of, for example, glistening fruits and vegetables or a spa-like setting) ${ }^{(12)}$. Thus, while sometimes the way in which the tests are sold and marketed indicate the seriousness of the test, at other times such differences are simply rhetorical, reflecting the chosen marketing strategy of the company.

On the whole, the DTC genetic testing companies seem to oversell their services, with a substantial portion not appropriately disclosing the limits of the science behind the tests. There were differences between companies, whole genome testing services faring better, but hardly any companies fully discussed the limited predictive power of the tests, in a situation where new genetic risk factors are continuously being discovered and their interaction with multiple environmental factors mostly remains an unresolved puzzle. The companies mobilised a sense of empowerment, expertise and warmth to market their tests, typical strategies in marketing, and online marketing especially, to enhance customers' sense of agency as well as pleasure and positivity associated with the service ${ }^{(17)}$. Some companies framed their tests more as medical and others more as lifestyle products, of those companies selling the tests directly online only a minority provided advice by a healthcare professional for those seeking more assistance.

While there was variation between companies, the current research indicates that the information provided by DTC genetic testing companies was often potentially misleading.

\section{User experiences of direct-to-consumer genetic tests}

The main concern about DTC genetic testing has, indeed, been that it may misguide consumers and worry them, i.e. make them unnecessarily anxious about health risks or wrongly reassure them about lack of risk ${ }^{(2,3)}$. The benefit of genetic testing for lifestyle-related diseases, suggested by the commercial companies as well as public policy ${ }^{(18)}$, is that it could encourage individuals to change their behaviour.

Several recent studies on how users respond to whole genome scans have observed that they seem to have no major negative or positive effects or engender major misunderstandings. A before and after study on 2037 consumers who had been offered Navigenics' Health Compass at a reduced price reported no changes in anxiety, fat intake, exercise levels or rate of use of screening three months after the test. Only 10\% of the consumers had consulted a genetic counsellor, which was offered free of charge, but $26 \%$ had shared their results with a physi$\operatorname{cian}^{(19)}$. In a trial ( $n$ 345) comparing the responses of those patients who had received usual care or usual care plus a modified version of the Navigenics test, James et al. reported increased initial perception of risk for most conditions and lower perceived risk for prostate cancer. However, at one-year follow-up the difference had disappeared, further supporting a null hypothesis for the effects of DTC genetic testing ${ }^{(20)}$.

Such findings are unsurprising against studies that have examined psychological and behavioural effects of genetic susceptibility testing in clinical settings and have frequently found modest or no effects. A recent review of trials on whether genetic tests for susceptibility to lung cancer encourage smoking cessation concluded that the findings did not suggest that genetic information would add value to existing smoking cessation programmes. However, there were positive effects among some subgroups. The few studies on genetic susceptibility for obesity and heart disease have found that providing genetic information does not increase fatalism, i.e. sense that nothing can be done to prevent the condition, but does not encourage lifestyle change either ${ }^{(21)}$. There exist some smaller studies that have indicated that nutrigenetic information may motivate weight management or is perceived as more useful than ordinary dietary advice, but in the absence of further studies to corroborate these findings it is hard to assess their meaning ${ }^{(22,23)}$.

Qualitative studies, however, have indicated that there may be subgroups, who may take genetic susceptibility testing more seriously. Studies on patients' experiences of inherited susceptibility for breast cancer, heart disease, haemochromatosis and deep vein thrombosis have observed that genetic or familial risk information is considered salient, if individuals already perceive themselves at risk. Such a sense of vulnerability may derive from having personally experienced the disease, having family members who have developed the disease or have other risk factors, such as high cholesterol ${ }^{(24-28)}$. Such observations have been corroborated by a recent online survey of 3167 customers of whole genome testing companies. Kaufman et al. found that those customers, who had a personal or a family history of a disease or poorer selfreported health, were more likely to report that they would consider lifestyle changes ${ }^{(29)}$. Thus, while DTC genetic tests seem not to have major negative or positive effects on their customers in general, there may be subgroups, who may already perceive themselves at risk and take the results more seriously, either in a positive or possibly negative way.

Another concern has been that customers misunderstand DTC genetic tests and get unduly worried about their health or consider themselves not to be at risk. In the Multiplex study, which offered patients a genetic test, 
which included fifteen gene variants associated with eight lifestyle-related diseases participants' understanding was good. Of the 199 participants $80 \%$ correctly recalled their risk status for the eight conditions, and they did not interpret the results deterministically, i.e. in terms of genes being major determinants of disease. Participants did not report overly negative or positive emotions. Those with least deterministic views were better educated and white $^{(30)}$. While the findings are reassuring, it should be borne in mind that the information provided by the Multiplex study may not be comparable to information provided by DTC genetic testing companies. However, similar findings have also been obtained in a McGowan et al. qualitative study of twenty-three customers of whole genome testing companies. The customers were enthusiastic about the science, but aware of the limitations of the test ${ }^{(31)}$.

Studies have also explored individuals' motivations for purchasing DTC genetic tests. Su et al. ${ }^{(32)}$ analysed blogs and user-forum discussions of customers of DTC genetic testing companies and found that individuals' were motivated to purchase the tests to learn about their health. However, they were also driven by other motivations, such as curiosity, interest in genealogy, interest in participating in research and entertainment. McGowan et al. also found that most commonly individuals were motivated to purchase the test to learn about their health. However, more than a half of the customers had a professional interest in genetics and wanted to be on the 'vanguard' of adopting this new technology ${ }^{(31)}$. Individuals who chose to participate in the Multiplex study and have the genetic scan did not hold deterministic views about genes but believed genetic information to be valuable and were confident they could understand it ${ }^{(30)}$. Furthermore, individuals who know about and are interested in DTC genetic testing at the moment seem an exclusive and small group. A US population-based survey conducted in 2006 found that $14 \%$ of individuals were aware of nutrigenomic tests, and those aware were predominantly well-educated and white ${ }^{(33,34)}$. A UK survey in 2008 found that $13 \%$ were aware of personal genome testing. Incidentally, the customers of DTC genetic testing, including the participants in the reviewed studies, tend to be white, well-educated and wealthier than average $^{(19,20,35)}$

On the whole, based on current research DTC genetic testing seems not to engender major negative or positive effects, nor does it seem to lead to major misunderstandings about genetic determinism. There are at least three possible explanations to this. First, the early adopters of DTC genetic tests tend to be well-educated and privileged, hence their understanding could be good and psychological reactions muted. It has been argued that if such tests would be adopted more widely, they could create more misunderstandings and worry ${ }^{(36)}$. Second, risk information about lifestyle-related diseases rarely engenders significant behavioural or psychological reactions even in clinical settings. In this respect, online genetic tests join many other lifestyle interventions, the positive and negative impacts of which are often limited ${ }^{(37)}$. Third, it is conceivable that consumers of DTC genetic tests do not perceive them as medical services but more as consumer products marketed with health claims. Consumers typically interpret commercial messages with a pinch of salt; also health claims associated with food products are not taken at face value, but their credibility varies according to product, type of claim, cultural context and individuals' background $^{(38)}$. Furthermore, although users of DTC genetic tests frequently purchased the service to learn about their health, they also had other motives, such as curiosity and interest in science.

\section{Regulation of the tests}

Companies have been able to sell genetic tests online due to a loophole in regulation, which does not require inhouse or 'homebrew' laboratory tests to undergo pre-market review. Ever since the first tests were sold on the Internet in the early 2000 policy-makers in the UK, USA and elsewhere have discussed how to regulate them ${ }^{(5)}$

The discussion on whether and how to regulate DTC genetic tests has revolved around their validity and the benefits and harms the tests might engender. The analytical validity of the tests, focusing on whether the test accurately identifies the gene variant it is purported to identify, is regulated by laboratory regulation, such as them Clinical Laboratory Improvement Amendment accreditation. More challenging questions are clinical validity, i.e. whether the gene variant is associated with a specific disease and clinical utility, i.e. whether identifying the association has any health benefits. The majority of genetic tests offered DTC have limited clinical validity, because the discovered associations between a gene variant and a health condition, such as obesity, are only a minor part of the puzzle of interacting genetic and environmental factors, which account for an individual's body weight. As discussed in the previous section, the clinical utility, for example, the ability of these tests to encourage healthy behaviour, is also debatable.

However, the validity, utility and risks of the tests vary. Some single gene tests, such as the tests for a genetic predisposition to breast cancer (BRCA1 and BRCA2), have strong clinical validity (associated with $70-80 \%$ lifetime risk of breast cancer) but are also associated with significant psychological implications both for the individuals and their family members. On the contrary, nutrigenetic tests often include gene variants with tenuous clinical validity ${ }^{(1)}$, but based on research on effects of DTC genetic testing, they do not seem to cause significant psychological harm. For this reason, from early on regulators have suggested different genetic tests might need to be regulated differently.

Already in 2002 the UK Human Genetics Commission sought to distinguish between genetic tests with 'high,' 'intermediate' and 'low' impact ${ }^{39}$ ). Regulation of genetic tests has also revolved around how to categorize the tests. In Europe, genetic tests fall under the purview of the in vitro diagnostic medical devices directive. Discussions around the directive have focused on whether genetic tests, or which genetic tests, are considered medical devices. Further, as noted by a recent background document for the European Society for Human Genetics, the question has 
been whether genetic tests would fall under the risk category 'A', which would require pre-market review. Premarket review for diagnostic devices is far less stringent than for pharmaceuticals but, nevertheless, requires submission of clinical studies to gain approval and regulates truthfulness in labelling and promotional materials ${ }^{(40)}$. While the European Union regulation remains unclear, several member states, such as France and Germany, require that genetic tests are carried out by a doctor ${ }^{(41)}$. The UK allows the provision of DTC genetic testing. In the USA, there has been a debate over whether DTC genetic tests fall under the jurisdiction of the Food and Drug Administration. In 2006, in hearings in the US senate Committee on Ageing, after the condemning the Government Accountability Office report on the results of DTC genetic tests, Steve Gutman from the Food and Drug Administration concluded that the agency was working on establishing whether DTC genetic tests were medical devices and how they would be regulated ${ }^{(42)}$. In 2011, the Secretary's Advisory Committee on Genetics, Health and Society made a number of recommendations concerning oversight of DTC genetic tests, review of genetic testing claims and promotional materials and their clinical validity $^{(43)}$. In March 2011, the Food and Drug Administration held a meeting in which it indicated that it intended to regulate DTC genetic tests ${ }^{(44)}$, and the agency sent letters to DTC genetic testing companies requesting they submit their products and services to pre-market review. Even if the Food and Drug Administration actions indicated that the Agency was intending to regulate the DTC testing market, it still was not clear in 2012 what shape this regulation would take.

As noted by Wright and Zimmern, there are, in principle, three ways of responding to the regulatory challenge posed by DTC genetic tests. The libertarian option would be to allow the tests to be marketed without restrictions, as they do not cause direct harm (unlike pharmaceuticals). The conservative option would be not to allow any tests to be marketed without proven clinical utility and clinical support, because of potential harms, such as psychological distress and misguidance due to erroneous clinical information. The intermediate position would be to regulate the safety and accuracy of the tests and the validity of the marketing claims of the tests ${ }^{(45)}$. Many commentators agree that as 'a minimum' the claims made by DTC genetic testing companies should be reviewed and regulated ${ }^{(46)}$.

The likely outcome of deliberations on regulation will be a solution close to the intermediate position outlined earlier, i.e. the basic safety and accuracy of the tests and their marketing claims will be regulated. Such a development is likely as there has been no indication that the tests produce major harms, a political compromise is appealing and the neo-liberal historical political climate does not favour prohibitive regulation in general.

\section{Discussion}

Selling genetic tests on the Internet may seem an extraordinary idea. However, rather than being a unique phenomenon, the trends identified by current research indicate the technology is associated with general, historical developments transforming health and medicine.

In the early twenty-first century the notion of science and medicine as autonomous and authoritative sources of 'truth' is waning. This is witnessed by, for example, the fact that the lay public increasingly questions science, as happened in the controversy over GM crops. The authority of science is also challenged by its increasing enmeshment with commercial interests ${ }^{(47)}$. These historical developments are reflected in current research, which suggests that DTC genetic testing companies exaggerate the predictive powers of the tests, even if they also hedge their claims. The marketing of DTC genetic tests mobilises the authority of science to sell the tests, but it also erodes faith in science by using obviously commercial advertising rhetoric and, at least in some cases, by presenting information on the limits of the science behind the services.

The traditional notion of the patient, who submits to doctor's authority, is also giving way to 'expert patients', who want to be treated as equal partners in making decisions about their health and health-care and consult the Internet to acquire information on and manage their health $^{(48)}$. Simultaneously, health is becoming the responsibility of individuals rather than primarily the health-care system. However, theorists of the information society point out that the proliferation of commercial and other information inviting audience engagement produces individuals, who may be fascinated by the ubiquitous media and other messages but, at a deeper level, become indifferent to them ${ }^{(49)}$. Research on customers of DTC genetic tests indicate that they seem, indeed, to behave as expert patients, capable of acquiring and evaluating health information on their own, as they do not end up anxious or confused by the marketing information. However, the same lack of response applies to the motivational appeal of the tests, customers by and large not changing their health behaviours based on the results. The muted response of the customers mirrors the contradictions of information society, whereby individuals are increasingly engaged with information but, at the same time, remain disaffected by it. Nevertheless, these observations should be interpreted in light of the fact that the current users of DTC genetic tests tend to be educated, wealthy and white.

In a further historical development states are losing control over both lay and commercial activities due to globalization, liberalization and the Internet ${ }^{(50)}$. These developments make it increasingly difficult for states to control a phenomenon, such as DTC genetic testing, which incorporates new technology and commerce that crosses borders. Further, in the current political climate, favouring liberalization of the markets and facilitation of commerce, it is not likely that many governments or intergovernmental organizations, such as the European Union, will regulate DTC genetic tests in the strictest manner.

Critics have accused DTC genetic testing companies for not living up to expectations of traditional medicine, i.e. provide evidence-based serious information with potent positive and negative effects via an accredited professional. However, as I, and others, have suggested these tests are novel phenomena not necessarily obeying the logic of conventional medicine ${ }^{(12,51)}$. While the tests are 
marketed and consumed as health products, their marketing follows the hyperbole of consumer advertising; the current consumers of the tests do not seem to be majorly affected by the service, and the regulation of the tests is most likely to focus on consumer regulation, i.e. regulating the marketing claims. As such, the DTC genetic tests reflect the transformations in medicine in terms of erosion of the authority of scientific truth, individuals' increasing engagement with and indifference towards health and other information and diminishing of state authority and liberalization. DTC genetic tests are only one example of health products embodying these transformations; others include, for example, food-products associated with health claims. Health claims are also associated with varied scientific evidence, have been accused of misleading marketing, provoked varied consumer credibility, and policy-makers have responded to their challenge by regulating marketing somewhat differently in different countries.

The concern, rising from interpreting DTC genetic tests in traditional medical terms, that the tests harm individual consumers seem, based on current research, misdirected. Rather, the problem with DTC genetic tests is that they do not address major, contemporary public health issues and may, together with similar innovations, mask these real concerns. The major contemporary health issue is global health inequality, brought about by poverty, lifestyle-related diseases, old and new infectious diseases and perinatal conditions, which account for poor health and starkly short life expectancy in many developing countries. The major challenge facing developed countries is the epidemic in lifestyle-related diseases, which are generated by complex social processes affecting our diet and exercise and are significantly more prevalent among deprived individuals and regions. These problems cannot be resolved by innovative health products targeted at wealthy niche markets.

\section{Acknowledgements}

The research was funded by the Wellcome Trust's Biomedical Ethics Programme (grant no. 080126/Z/06/Z). The views expressed in the paper are the author's and do not reflect the funders' views. The author declares no conflict of interest.

\section{References}

1. Janssens AC, Gwinn M, Bradley LA et al. (2008) A critical appraisal of the scientific basis of commercial genomic profiles used to assess health risks and personalize health interventions. Am J Hum Genet 82, 593-599.

2. US Government Accountability Office (2010) Direct-to-consumer Genetic Tests Misleading Test Results Are Further Complicated by Deceptive Marketing and Other Questionable Practices. http://www.gao.gov/assets/130/125079.pdf

3. US Government Accountability Office (2006) Nutrigenetic Testing Tests Purchased from Four Web Sites Mislead Consumers. http://www.gao.gov/assets/120/114612.pdf

4. 23andMe (2011) 23andMe Database Surpasses 100000 Users. https://www.23andme.com/about/press/23andme_database_100000k_users/
5. Hogarth S, Javitt G \& Melzer D (2008) The current landscape for direct-to-consumer genetic testing: legal, ethical, and policy issues. Annu Rev Genomics Hum Genet 9, 161-182.

6. Lachance CR, Erby LA, Ford BM et al. (2010) Informational content, literacy demands, and usability of websites offering health-related genetic tests directly to consumers. Genet Med 12, 304-312.

7. Lewis N, Treise D, Hsu SI et al. (2011) DTC genetic testing companies fail transparency prescriptions. New Genet Soc 30, 291-307.

8. Singleton A, Erby LH, Foisie KV et al. (2012) Informed choice in direct-to-consumer genetic testing (DTCGT) websites: a content analysis of benefits, risks, and limitations. $J$ Genet Couns 21, 433-439.

9. Sterling R (2008) The on-line promotion and sale of nutrigenomic services. Genet Med Nov 10, 784-796.

10. Liu Y \& Pearson Y (2008) Direct-to-consumer marketing of predictive medical genetic tests: assessment of current practices and policy recommendations. J Public Policy Market 27, 131-148.

11. Harvey A (2010) Genetic risks and healthy choices: creating citizen-consumers of genetic services through empowerment and facilitation. Sociol Health Illn 32, 365-381.

12. Saukko PM, Reed M, Britten N et al. (2010) Negotiating the boundary between medicine and consumer culture: online marketing of nutrigenetic tests. Soc Sci Med 70, 744753.

13. Nordgren A \& Juengst ET (2009) Can genomics tell me who I am? Essentialist rhetoric in direct-to-consumer DNA testing. New Genet Soc 28, 157-172.

14. Einsiedel E \& Geransar R (2009) Framing genetic risk: trust and credibility markers in online direct-toconsumer advertising for genetic testing. New Genet Soc $\mathbf{2 8}$, 339-362.

15. Gollust SE, Wilfond BS \& Hull SC (2003) Direct-to-consumer sales of genetic services on the internet. Genet Med $\mathbf{5}$, 332-337.

16. Geransar R \& Einsiedel E (2008) Evaluating online direct-toconsumer marketing of genetic tests: informed choices or buyers beware? Genet Test 12, 13-23.

17. Prahalad CK \& Ramaswamy V (2004) Co-creation experiences: the next practice in value creation. $J$ Interact Market $18,5-14$.

18. Department of Health (2003) Our Inheritance, Our Future Realising the potential of genetics in the NHS London. http:// www.dh.gov.uk/prod_consum_dh/groups/dh_digitalassets/ @ dh/@en/documents/digitalasset/dh_4019239.pdf

19. Bloss CS, Schork NJ \& Topol EJ (2011) Effect of direct-toconsumer genomewide profiling to assess disease risk. $N$ Engl J Med 10, 364, 524-534.

20. James KM, Cowl CT, Tilburt JC et al. (2011) Impact of direct-to-consumer predictive genomic testing on risk perception and worry among patients receiving routine care in a preventive health clinic. Mayo Clin Proc 86, 933940.

21. McBride CM, Koehly LM, Sanderson SC et al. (2010) The behavioral response to personalized genetic information: will genetic risk profiles motivate individuals and families to choose more healthful behaviors? Annu Rev Public Health 31, 89-103.

22. Arkadianos I, Valdes AM, Marinos E et al. (2007) Improved weight management using genetic information to personalize a calorie controlled diet. Nutr J 6, 29.

23. Nielsen DE \& El-Sohemy A (2012) A randomized trial of genetic information for personalized nutrition. Genes Nutr 7 , $559-566$. 
24. Hall R, Saukko PM, Evans PH et al. (2007) Assessing family history of heart disease in primary care consultations: a qualitative study. Fam Pract 24, 435-442.

25. Walter FM, Emery J, Braithwaite D et al. (2004) Lay understanding of familial risk of common chronic diseases: a systematic review and synthesis of qualitative research. Ann Fam Med 2, 583-594.

26. Saukko PM, Richards SH, Shepherd MH et al. (2006) Are genetic tests exceptional? Lessons from a qualitative study on thrombophilia. Soc Sci Med 63, 1947-1959.

27. Bharadwaj A (2002) Uncertain risk: genetic screening for susceptibility to haemochromatosis. Health Risk Soc $\mathbf{4}$, 227-240.

28. Hallowell N, Foster C, Eeles R et al. (2004) Accommodating risk: responses to BRCA1/2 genetic testing of women who have had cancer. Soc Sci Med 59, 553-565.

29. Kaufman DJ, Bollinger JM, Dvoskin RL et al. (2012) Risky business: risk perception and the use of medical services among customers of DTC personal genetic testing. J Genet Couns 21, 413-422.

30. McBride CM, Wade CH \& Kaphingst KA (2010) Consumers' views of direct-to-consumer genetic information. Annu Rev Genomics Hum Genet 11, 427-446.

31. McGowan ML, Fishman JR \& Lambrix MA (2010) Personal genomics and individual identities: motivations and moral imperatives of early users. New Genet Soc 29, 261-290.

32. Su Y, Howard HC \& Borry P (2011) Users' motivations to purchase direct-to-consumer genome-wide testing: an exploratory study of personal stories. J Community Genet 2, 135-146.

33. Goddard KA, Duquette D, Zlot A et al. (2009) Public awareness and use of direct-to-consumer genetic tests: results from 3 state population-based surveys, 2006. Am J Public Health 99, 442-445.

34. Cherkas LF, Harris JM, Levinson E et al. (2010) A survey of UK public interest in internet-based personal genome testing. PLOS ONE 5, e13473.

35. Kaphingst KA, McBride CM, Wade C et al. (2012) Patients' understanding of and responses to multiplex genetic susceptibility test results. Genet Med 14, 681-687.

36. Hogarth S (2010) Myths, misconceptions and myopia: searching for clarity in the debate about the regulation of consumer genetics. Public Health Genomics 13, 322326.

37. Ebrahim S, Taylor F, Ward K et al. (2011) Multiple risk factor interventions for primary prevention of coronary heart disease. Cochrane Database Syst Rev 1, CD001561.
38. Wills JM, Storcksdieck genannt Bonsmann S, Kolka M et al. (2012) European consumers and health claims: attitudes, understanding and purchasing behaviour. Proc Nutr Soc FirstView, 1.

39. Human Genetics Commission (2002) Inside Information Balancing Interests in the use of Personal Genetic Data.

40. Becker F, van El CG, Ibarreta D et al. (2011) Genetic testing and common disorders in a public health framework: how to assess relevance and possibilities. Background Document to the ESHG recommendations on genetic testing and common disorders. Eur J Hum Genet 19, Suppl. 1, S6-S44.

41. Borry P, van Hellemondt RE, Sprumont D et al. (2012) Legislation on direct-to-consumer genetic testing in seven European countries. Eur J Hum Genet 20, 715-721.

42. Steve G (2006) Statement Safety and Quality of In Vitro Diagnostic Devices (IVDs). http://www.fda.gov/NewsEvents/ Testimony/ucm111048.htm

43. Secretary's Advisory Committee on Genetics, Health, and Society (2010) Direct-to-Consumer Genetic Testing Report of the Secretary's Advisory Committee on Genetics, Health, and Society. http://oba.od.nih.gov/oba/sacghs/reports/ SACGHS_DTC_Report_2010.pdf

44. Food and Drug Administration (2011) Summary from the Molecular \& Clinical Genetics Panel Meeting, 8-9 March 2011. http://www.fda.gov/downloads/AdvisoryCommittees/ CommitteesMeetingMaterials/MedicalDevices/MedicalDevicesAdvisoryCommittee/MolecularandClinicalGneticsPanel/ UCM246907.pdf

45. Wright CF, Hall A \& Zimmern RL (2011) Regulating directto-consumer genetic tests: what is all the fuss about? Genet Med 13, 295-300.

46. Caulfield T (2011) Direct-to-consumer testing: if consumers are not anxious, why are policymakers? Hum Genet 130, 23-25.

47. Nowotny H, Scott P \& Gibbons X (2001) Re-thinking Science: Knowledge and the Public in an Age of Uncertainty. London: Polity.

48. Nettleton S (2004) The emergence of e-scaped medicine. Sociology 38, 661-79.

49. Baudrillard J (1977) The implosion of meaning in the media and the implosion of the social in the masses. In The Myth of Information: Technology and Postindustrial Culture [Woodward K, editor]. Madison, USA: Coda Press.

50. Castells M (1996) The Rise of the Network Society. London: Blackwell.

51. Prainsack B, Reardon J, Hindmarsh R et al. (2008) Personal genomes: misdirected precaution. Nature 456, 34-35. 